\section{PC-039 OPTIMISATION OF MIXING AN ORAL POWDER MIXTURE OF CODEINE PREPARED IN THE HOSPITAL PHARMACY FOR FILLING INTO HARD CAPSULES}

'L Bouz*, 'S Klovrzová, ${ }^{2} \mathrm{~L}$ Matysová. 'Institute for Clinical and Experimental Medicine, Hospital Pharmacy, Prague, Czech Republic; ${ }^{2}$ Charles University-Faculty of Pharmacy, Department of Analytical Chemistry, Hradec Králové, Czech Republic

\subsection{6/ejhpharm-2020-eahpconf.86}

Background and importance Codeine mixed with calcium salts filled into capsules is used to treat chronic diarrhoea in transplant, oncological and geriatric patients, and in patients with irritable bowel disease. At least 11500 hard capsules are regularly prepared from a manually blended powder mixture in the hospital pharmacy per month. Turbula 2F2 blender has been introduced into the hospital pharmacy to optimise the mixing process.

Aim and objectives To establish optimal blending time and speed for mixing of codeine with the Turbula 2F2 blender and to verify homogeneity by determining the amount of codeine in the samples, a validated spectrophotometric analytical method was used.

Material and methods The total amount of prepared mixture was $245.7 \mathrm{~g}$ containing $4.5 \mathrm{~g}$ of codeine phosphate (1.83\%). The optimal rotation speed of Turbula was established as 49 rounds per min (RPM) based on visual analysis with colourant instead of codeine.

A 2 litre polyethylene container for homogenisation was used. Calcium carbonate was premixed with colloidal silica, and codeine and tricalcium phosphate added. Five samples for analysis were taken from different places in the container after $5,10,15$ and $20 \mathrm{~min}$ of mixing. Expression of relative standard deviation (RSD) was used to evaluate the homogeneity of codeine in the mixture.

Results The results are summarised in table 1 .

Conclusion and relevance Based on the results, the optimal time of 10 min was estimated for mixing of the codeine mixture at $49 \mathrm{RPM}$. The use of the Turbula $2 \mathrm{~F} 2$ mixer was

\begin{tabular}{|c|c|c|c|}
\hline Time of mixing at 49 RPM & Sample No & Content of codeine $(\%)$ & RSD \\
\hline \multirow[t]{5}{*}{$5 \mathrm{~min}$} & 1 & 1.84 & 2.47 \\
\hline & 2 & 1.79 & \\
\hline & 3 & 1.77 & \\
\hline & 4 & 1.79 & \\
\hline & 5 & 1.89 & \\
\hline \multirow[t]{5}{*}{$10 \mathrm{~min}$} & 6 & 1.75 & 1.91 \\
\hline & 7 & 1.72 & \\
\hline & 8 & 1.74 & \\
\hline & 9 & 1.72 & \\
\hline & 10 & 1.81 & \\
\hline \multirow[t]{5}{*}{$15 \mathrm{~min}$} & 11 & 1.59 & 3.82 \\
\hline & 12 & 1.73 & \\
\hline & 13 & 1.76 & \\
\hline & 14 & 1.62 & \\
\hline & 15 & 1.64 & \\
\hline \multirow[t]{5}{*}{$20 \mathrm{~min}$} & 16 & 1.58 & 5.47 \\
\hline & 17 & 1.69 & \\
\hline & 18 & 1.74 & \\
\hline & 19 & 1.49 & \\
\hline & 20 & 1.67 & \\
\hline
\end{tabular}

beneficial in reducing pharmacy staff exposure to powder particles of hazardous drugs and in reducing the risk of cross contamination in the laboratory.

\section{REFERENCES AND/OR ACKNOWLEDGEMENTS}

No conflict of interest.

\section{PC-040 GALENIC VALIDATION OF A DEXAMETHASONE $0.01 \%$ MOUTHWASH SOLUTION TO PREVENT EVEROLIMUS RELATED STOMATITIS}

J Vicente Valor*, JL Herrero Revuelta, MS Pernia López, A Herranz Alonso, M Sanjurjo Sáez. Gregorio Marañón University General Hospital, Pharmacy Service, Madrid, Spain

\subsection{6/ejhpharm-2020-eahpconf.87}

Background and importance Stomatitis is a common adverse drug reaction of the mTOR inhibitor everolimus. Rugo et al (2016) reported that the use of a dexamethasone mouthwash solution prevented everolimus related grade $>2$ stomatitis in patients with hormone receptor positive and HER2 negative metastatic breast cancer. No commercial presentation is available in our country, and so we carried out galenic validation of a formulation for these patients.

Aim and objectives The aim of this study was to develop a dexamethasone $0.01 \%$ stable solution for mouth washing to prevent stomatitis in patients started on everolimus treatment. Material and methods We designed two formulations based on the components of a commercial oral preparation manufactured in USA by Roxane Laboratories. We added EDTA to explore if this affected stability (table 1 ).

\begin{tabular}{ll} 
Abstract 3PC-040 Table 1 \\
\hline \begin{tabular}{ll}
\hline Dexamethasone phosphate $4 \mathrm{mg} / \mathrm{mL}$ injectable ampule (Kern Pharma) & $10 \mathrm{mg} / 2.5 \mathrm{~mL}$ \\
Preservative water containing methylparaben (9\%) and propylparaben & qs $100 \mathrm{~mL}$ \\
$(2.2 \%)$ & \\
Citric acid solution $25 \%$ & qs pH $3-5$ \\
Sodium edetate* & $10 \mathrm{mg}$ \\
\hline qs, quantum sufficit. & \\
*Only added in one solution.
\end{tabular}
\end{tabular}

For assignment of the microbiological validity period, we used the risk matrix from Good Manufacture Practices of Hospital Pharmacy. We preserved both solutions under room temperature and refrigeration conditions, always protected from light. We checked for organoleptic characteristics (cleanness, colour, odour, flavour) and $\mathrm{pH}$ every week for 30 days.

Results We obtained transparent, homogenous solutions free of visible and rare particles. Physicochemical stability was guaranteed as we used a pre-existing formulation to develop our preparation. Furthermore, organoleptic characteristics were constant and $\mathrm{pH}$ remained stable between 3 and 5 . We selected the formula without EDTA because its manufacture was easier. We assigned a beyond use date of 30 days, keeping the formulation refrigerated and protected from light.

Conclusion and relevance This formulation was simple to prepare. It can be used in other hospitals for the same purpose and has filled a therapeutic void. Clinical effectiveness might be investigated to confirm the utility of this magistral formula. 
REFERENCES AND/OR ACKNOWLEDGEMENTS

1. Rugo HS, et al. Lancet Oncol 2017;18:654-662.

No conflict of interest.

\section{PC-041 SURFACE CONTAMINATION WITH CYTOTOXIC DRUGS IN EUROPEAN HOSPITAL WARDS}

${ }^{1} \mathrm{E}$ Korczowska*, ${ }^{1} \mathrm{H}$ Jankowiak-Gracz, ${ }^{2} \mathrm{M}$ Crul, ${ }^{3}$ J Tuerk, ${ }^{4} \mathrm{D}$ Arnold, ${ }^{5} \mathrm{~K}$ Meier. ${ }^{1}$ University Hospital of Lord's Transfiguration, Hospital Pharmacy, Poznan, Poland; ${ }^{2}$ Amsterdam University Medical Centre, Department of Clinical Pharmacology and Pharmacy, Amsterdam, The Netherlands; ${ }^{3}$ Institute of Energy and Environmental Technology, luta, Duisburg, Germany; ${ }^{4}$ Department of Medical Oncology, Klinik Für Tumorbiologie, Freiburg, Germany; 5 Institute For Applied Healthcare Sciences, Ifahs, Hamburg, Germany

\subsection{6/ejhpharm-2020-eahpconf.88}

Background and importance Several studies have shown that antineoplastic drug contamination is found on various work surfaces in hospitals and varies widely on wards. The MASHA project (research about environmental contamination by cytotoxics and management of safe handling procedures) was to set up to conduct new research, in cooperation with the European Society for Medical Oncology, into contamination levels in hospital wards.

Aim and objectives To obtain an overview of the current levels of cytotoxic contamination in European hospital wards and increase awareness among healthcare workers and their employers about the risks associated with working with hazardous drugs, and to provide them with additional measures to improve safety.

Material and methods The assessment of surface contamination with cytotoxic drugs was done by evaluating wipe samples collected from four comparable surfaces on the wards (work benches, floors, armrest of patient's chair and lids of waste containers). Each sample was analysed for the presence of five commonly used cytotoxic drugs (cyclophosphamide, 5-fluorouracil, paclitaxel, gemcitabine and total platinum for platinum drugs), using ICP-MS for total platinum and LC-MS/MS for other substances.

Results The database includes results collected from 28 hospital units from 16 European countries. Of the 560 samples collected, 268 were positive (48\%). Measurable amounts of at least one substance were detected on investigated surfaces in every hospital: 21/28 (75\%) hospitals had over 30\% positive samples. Contamination was detected mostly on the floors (58\%), armrests (50\%), lids (42\%) and work benches $(40 \%)$. The highest values were found for cyclophosphamide $\left(380 \mathrm{ng} / \mathrm{cm}^{2}\right)$ and 5 -fluorouracil $\left(130 \mathrm{ng} / \mathrm{cm}^{2}\right)$ on the lids. The highest number of positive results were recorded with platinum drugs (33\%), 5-fluorouracil (25\%), gemcitabine (19\%) and cyclophosphamide (18\%). Substances were detected on $45 / 112$ of surfaces (40\%) which had not been used for cytotoxic drug preparation on the day of the wipe sampling.

Conclusion and relevance Contamination is detectable on the ward but at different levels in different hospitals. Cleaning procedures are still not effective. Therefore, evaluation of exposure of healthcare workers is crucial. Greater collaboration with medical and nurse societies, to improve safe handling procedures in hospitals and thus improve the safety of all healthcare workers, is required.
REFERENCES AND/OR ACKNOWLEDGEMENTS

No conflict of interest.

\section{PC-042 THE SIGNIFICANCE OF PHARMACY PREPARATION IN PAEDIATRICS: MAKING INDIVIDUAL THERAPIES FOR CRITICALLY ILL CHILDREN POSSIBLE}

B Verdino*, K Nemec. Donauspital, Hospital Pharmacy, Vienna, Austria

\subsection{6/ejhpharm-2020-eahpconf.89}

Background and importance The 1000 bed Donauspital, Vienna, provides all types of care for children, including a paediatric intensive care unit (PICU) and a neonatal intensive care unit (NICU). Pharmacotherapy in paediatrics is often limited because no licensed medication is available for the condition of the child or, if available, the dosage is not correct for age and/or developmental stage. Therefore, individually manufactured medicines play an important role in the therapy of children.

As we had to assess the appropriateness of our allocation of human resources, we conducted this study to find out what amount of manufactured medicines are needed to treat our paediatric patients.

Aim and objectives We investigated the extent of individually manufactured medications for children in our hospital (figure 1). These medications included all types of dosage forms (eg, capsules, suppositories, intravenous preparations and compounded solutions for parenteral nutrition (TPN)) to see if drug therapy in critically ill children can be successful without manufacturing in the pharmacy and to evaluate the significance of pharmacy production.

Material and methods For three months (May to July 2019) all prescriptions for patients in the PICU and NICU were recorded from the critical care information system of the hospital. We compared the number of individually manufactured medications with the number of drugs used that were commercially available. All drugs were counted once per used dosage, even when prescribed several times for the same patient. We also counted TPN only once per patient (one solution containing amino acids, electrolytes and trace elements and one lipid emulsion containing vitamins), although the amount of the components prescribed changed almost daily.

Results During our study period in both the PICU and NICU, 99 children were hospitalised and treated with 1286

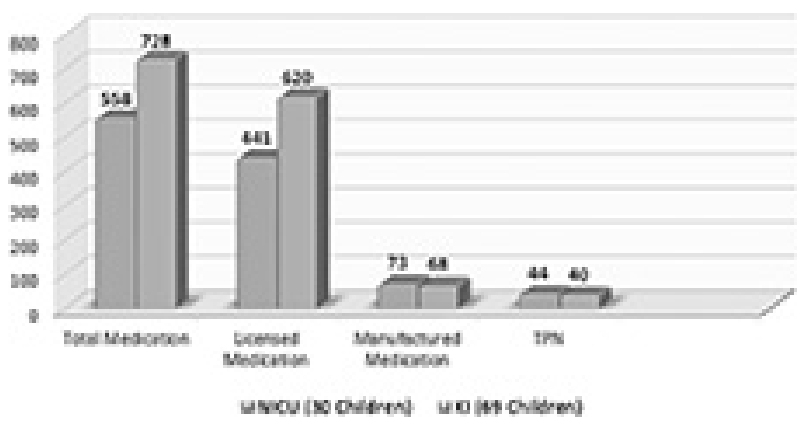

Abstract 3PC-042 Figure 1 Comparison of individually manufactured and commercially available medications used in the NICU and PICU 